\title{
A PRODUÇÃO DO CONHECIMENTO SOBRE A RELAÇÃO ESCOLA E FAMÍLIA EM 13 ANOS DE ANPED
}

\author{
KNOWLEDGE PRODUCTION ON THE SCHOOL AND FAMILY \\ RELATION IN 13 YEARS OF ANPED
}

\section{LA PRODUCCIÓN DEL CONOCIMIENTO SOBRE LA RELACIÓN ESCUELA Y FAMILIA EN TREZE AÑOS DE ANPED}

\begin{abstract}
Letícia Veiga Casanova*
Professora do curso de Pedagogia na Universidade do Vale do Itajaí; integrante do Grupo de Pesquisa Contextos da Educação da Criança

Valéria Silva Ferreira**

Professora titular da Universidade do Vale do Itajaí, atua no curso de Pedagogia e no Mestrado/Doutorado em Educação; Lidera o Grupo de Pesquisa Contextos da Educação da Criança
\end{abstract}

Resumo: Neste artigo se objetivou analisar a produção do conhecimento acerca da relação escola e família a partir dos trabalhos comunicados nas reuniões anuais da ANPEd entre o período de 2000 e 2013. A coleta dos trabalhos aconteceu por meio da homepage do evento, em todos os Grupos de Trabalho (GT). Com um corpus de 44 trabalhos, a análise estabeleceu-se em dois momentos. O primeiro, agrupando os trabalhos por GT, o que possibilitou observar a área da Sociologia da Educação com quase metade dos trabalhos. O segundo momento desenvolveu-se a partir da leitura dos trabalhos e reconhecimento da questão central de cada um, levando a quatro categorias definidas a posteriori: interação, representações, políticas educacionais e práticas e perfis familiares.

Palavras-chave: Relação família e escola. Ensino Fundamental. Educação Infantil.

\footnotetext{
* Mestre em Educação pela Universidade do Vale do Itajaí; graduada em Pedagogia pela Universidade do Vale do Itajaí.

** Doutora em Educação (Psicologia da Educação) pela Pontifícia Universidade Católica de São Paulo.
} 
Abstract: In this paper aimed to analyze the production of knowledge about school and family relationship from the reported work at the annual meetings of ANPED in the 2000-2013 period. The collection of works took place through the homepage of the event, in all Working Groups (GT). With a corpus of 44 works, the analysis was established in two moments. The first, by grouping works by GT, which enabled us to observe the area of Sociology of Education with almost half of the work. The second moment was developed from the reading of the works and recognition of the central question of each one, leading to four ex post facto categories: interaction, representations, educational policies and practices and family profiles.

Keywords: Family and school relation. Elementary School. Child Education.

Resumen: Este artículo tiene como objetivo analizar la producción de conocimiento sobre la relación de la escuela y la familia desde presentaciones de artículos en las reuniones anuales de ANPED entre los años 2000 y 2013. La colecta de los datos, se dio a través de la homepage del evento, en todos los Grupos de trabajo (GT). Con un corpus de 44 artículos, el análisis se estableció en dos etapas. La primera, desde la agrupación de las obras por GT, que nos permitió observar el área de la sociología de la educación, con casi la mitad de los artículos. La segunda etapa se desarrolló a partir de la lectura de los artículos y del reconocimiento de la cuestión central de cada uno, lo que lleva a cuatro categorías así definidas: interacción, las representaciones, las políticas educativas y prácticas y perfiles de la familia.

Palabras clave: Relación familia y escuela. Enseño fundamental. Educación Infantil.

\section{INTRODUÇÃO}

A educação das crianças, por muito tempo, foi considerada responsabilidade única da família e do grupo social ao qual pertenciam. Era com os adultos e demais crianças que se aprendia a se tornar membro de um grupo, participar das tradições consideradas importantes e apropriar-se de conhecimentos que lhes seriam necessários para a vida adulta. Por um bom período da história da humanidade, nenhuma instituição se incumbiu de compartilhar a responsabilidade pela criança com seus pais e com a comunidade da qual fazia parte (KUHLMANN JÚNIOR; FERNANDES, 2004).

Contudo, como define Rosemberg (1995), os movimentos de liberação da mulher nos anos 1960 e 1970 diminuíram a distância entre papéis masculinos e femininos, incentivaram a participação das mulheres no mercado de trabalho e questionaram o exercício da maternidade como o único destino feminino. Dessa forma, a 
educação das crianças começou a ser compartilhada e definida pela Constituição Federal (BRASIL, 1988, p. 137), em seu Art. 205, como: “A educação, direito de todos e dever do Estado e da família, será promovida e incentivada com a colaboração da sociedade, visando ao pleno desenvolvimento da pessoa, seu preparo para o exercício da cidadania e sua qualificação para o trabalho."

$\mathrm{Na}$ contemporaneidade, observa-se mais um fenômeno de mudança. Os novos arranjos familiares distanciam-se dos padrões familiares considerados típicos da sociedade moderna: a família nuclear. Há, assim, uma reorganização das relações entre família e sociedade e, por consequência, das relações entre as famílias e as instituições complementares, como as creches, as pré-escolas e as escolas. São duas referências, família e professor, que se relacionam diante de um ponto em comum: a educação das crianças.

Entre os pesquisadores que dedicaram sua produção a investigar a relação entre família e instituição escolar, há um consenso de que uma boa relação entre escola ${ }^{1}$ e famílias é um critério de qualidade importante para o desenvolvimento das crianças (KISHIMOTO; HADDAD, 1995; BHERING; GARCIA, 1999, 2001; BHERING; NEZ, 2002; BHERING; MACHADO, 2004; CORSINO, 2002; VASCONCELOS, 2001, 2004; ROSSETTI-FERREIRA; AMORIM, 1997, 1998; SZYMANSKI, 2010).

No entanto, o que mais se tem pesquisado sobre a relação escola e família? O que as pesquisas nos apontam? Sabendo da importância que a Associação Nacional de Pós-Graduação e Pesquisa em Educação (ANPEd) tem em promover o desenvolvimento de pesquisas em educação, buscamos responder a essas perguntas partindo dos trabalhos apresentados nas reuniões anuais da ANPEd.

AANPEd é uma associação que congrega programas, professores e estudantes de pós-graduação stricto sensu em educação e tem por finalidade o desenvolvimento da ciência, da educação e da cultura. Como afirmam Sousa e Bianchetti (2007, p. 394):

A ANPEd, como fórum de debates e divulgação do que se re-
aliza na pós-graduação, além de promover a interlocução en-
tre pesquisadores, é reconhecida como espaço de qualificação
das produções acadêmicas, por meio do Comitê Científico, dos
grupos de trabalho, do Fórum de Coordenadores, das reuniões
anuais, espaços estes de exposição e diálogo sobre as pesquisas
e a formação realizadas em todo o Brasil.

Observamos, assim, a importância das discussões e das reflexões apresentadas nas reuniões da ANPEd, contribuindo para o aprofundamento e a sistematização dos estudos, bem como a comunicação de novas questões de pesquisa e bases teóricas. Assim, este trabalho foi desenvolvido com o objetivo de analisar a produção do co- 
nhecimento acerca da relação escola e família a partir dos trabalhos comunicados nas reuniões anuais da ANPEd entre o período de 2000 a 2013.

O levantamento dos trabalhos considerou esse período cronológico por reconhecer a implementação de políticas que incentivam a relação entre escola e famílias, como Campanha Nacional da Família na Escola (2001), Programa Nacional de Fortalecimento dos Conselhos Escolares (2004) e Mobilização Social pela Educação (2008), que surgiram após o ano 2000.

A busca pelos trabalhos foi realizada a partir do acesso ao Portal da ANPEd, nos 24 Grupos de Trabalho (GT) permitindo, assim, a contribuição dos diferentes campos do conhecimento, pois cada GT reúne pesquisadores de diferentes áreas.

Selecionamos os trabalhos a partir dos seguintes descritores encontrados em seu título e/ou resumo: família e escola, relação família-escola, relação família-creche, relação pais e escola, interação família-escola, envolvimento família-escola e participação das famílias. Com esses descritores, garantimos a seleção dos trabalhos que definissem o objeto de estudo como algum tipo de relação, interação ou participação entre as duas instituições.

A partir dos descritores, levantamos 44 trabalhos, e a análise desse material estabeleceu-se em dois momentos. O primeiro, agrupando os trabalhos por GT, o que nos possibilitou observar a representação das diferentes áreas. E o segundo momento desenvolveu-se a partir da leitura dos trabalhos e reconhecimento da questão central de cada um. Dessa forma, a leitura dos trabalhos levou-nos a quatro categorias definidas a posteriori e que descrevemos como o movimento das pesquisas.

Dessa forma, o artigo apresenta-se em dois momentos: as diferentes áreas do conhecimento e o movimento acerca dos trabalhos sobre a relação escola e família.

\section{AS DIFERENTES ÁREAS DO CONHECIMENTO NA PRODUÇÃO SOBRE A RELAÇÃO ESCOLA E FAMÍLIA}

Por meio da análise sobre um corpus de 44 trabalhos selecionados, apresentamos o movimento que os estudos sobre a relação escola e família vêm estabelecendo nas reuniões anuais da ANPEd desde o ano 2000.

A primeira análise foi feita a partir do número de trabalhos apresentados em cada GT. Os 44 trabalhos selecionados foram apresentados em oito dos 24 Grupos de Trabalho, assim distribuídos: 
Quadro 1 - Grupos de Trabalho da ANPEd e número de trabalhos apresentados sobre relação escola e família (ANPED, 2000 - 2013)

\begin{tabular}{ll}
\hline Grupos de Trabalho & Número de trabalhos apresentados \\
\hline Sociologia da Educação & 21 \\
Educação de Crianças de 0 a 6 anos & 8 \\
Psicologia da Educação & 5 \\
Educação Fundamental & 3 \\
Estado e Política Educacional & 3 \\
Educação Especial & 2 \\
Trabalho e Educação & 1 \\
Afro-brasileiros e Educação & 1 \\
\hline
\end{tabular}

Fonte: $o$ autor.

É importante reconhecer como estão representadas as diferentes áreas. Observamos que a maioria dos trabalhos $(65,9 \%)$ foi apresentada nos Grupos de Trabalho da Sociologia da Educação e da Educação de Crianças de 0 a 6 anos.

Destacamos a produção do GT da Sociologia da Educação, que representa quase metade $(47,7 \%)$ dos trabalhos comunicados. O crescimento dos estudos dessa área voltados a analisar a relação escola e famílias também é afirmado por Romanelli, Nogueira e Zago (2013). Os autores destacam que, no curso de uma década e meia, houve mudanças intensas na vida política e econômica do País, nos estabelecimentos de ensino, nas políticas e práticas educativas, na organização e na composição das famílias, repercutindo no processo de escolarização e nas relações entre as duas instituições socializadoras. E, simultaneamente, no plano teórico, as abordagens da sociologia da educação ganharam novos aportes teóricos e metodológicos, enriquecendo esse campo de estudo.

A Sociologia da Educação também ganha destaque nas reuniões da ANPEd, reconhecendo-se, assim, como a área que mais investiga sobre a relação escola e família nas reuniões anuais; diferentemente do que acontece nas produções de dissertações e teses, nas quais se destacam as áreas da Educação e Psicologia (TOCI-DIAS, 2009). Dessa forma, as pesquisas da área da Sociologia da Educação sobre a relação escola e família aparecem de forma mais significativa nas reuniões anuais da ANPEd, pois encontram o espaço dessa área.

No GT da Educação de Crianças de 0 a 6 anos, com 18,1\% dos trabalhos, constatamos que metade deles está relacionada a pesquisas desenvolvidas na creche. Esses dados mostram o crescente movimento da Educação Infantil e da educação das crianças bem pequenas como campo de pesquisa. Porém, apesar de o GT da Educação de Crianças de 0 a 6 anos representar parte significativa dos trabalhos, observamos 
que, entre os trabalhos apresentados em todos os Grupos de Trabalho das reuniões anuais da ANPEd, prevalece a pesquisa desenvolvida no Ensino Fundamental com 34 trabalhos comunicados. A relação escola e família na Educação Infantil é representada por 10 trabalhos apresentados nos Grupos de Trabalho da Educação de Crianças de 0 a 6 anos e da Psicologia.

O GT da Psicologia também desenvolveu alguns trabalhos (11,3\%), porém, verificamos que estes foram comunicados até o ano 2006. Após essa data, não houve mais pesquisa apresentada sobre a relação escola e família. Os demais Grupos comunicaram de um a três trabalhos em 13 anos de produção analisada. Percebemos, assim, a falta de uma sistematização dos estudos sobre tal assunto.

Todos os trabalhos tratam diretamente da problemática da relação escola e família, porém, eles se diferenciam na questão central de cada trabalho, a qual pode ser observada a partir do movimento e das tendências apresentadas a seguir.

\section{O MOVIMENTO ACERCA DOS TRABALHOS SOBRE A RELAÇÃO ESCOLA E FAMÍLIA}

As pesquisas sobre a relação escola e família envolvem inúmeras discussões, como os tipos de relações estabelecidas na escola, a participação das famílias, as concepções e as expectativas de pais, professores e gestores sobre essa relação, a formação profissional, os perfis e as práticas familiares, o dever de casa, as políticas educacionais, entre tantas outras.

Contudo, de que forma a relação escola e família vem sendo tratada nas reuniões anuais da ANPEd? A resposta a essa pergunta traz a possibilidade de visualizar as pesquisas sobre a relação escola e família, apresentando o interesse dos pesquisadores da área da educação.

Após a leitura dos resumos dos trabalhos e identificação da questão central de cada pesquisa, identificamos quatro grandes focos de interesse nos últimos 13 anos. São eles: interação, representações, políticas educacionais e práticas e perfis familiares. O foco definido como interação se volta aos trabalhos que buscam as diferentes formas de contato, de negociações, das interconexões, da participação, dos desafios e das transformações da relação entre escola e famílias. As representações traduzem-se pelas pesquisas que investigam as crenças, as concepções, as expectativas e os sentidos e/ou significados atribuídos por familiares, professores e gestores sobre a relação entre família e escola. As políticas educacionais referem-se a pesquisas sobre as ações do Governo Federal, Estadual ou Municipal e traduzem-se na análise da legislação, de 
programas e/ou de documentos. As práticas e os perfis familiares são pesquisas que investigam o envolvimento e a influência dos familiares no processo de escolarização das crianças segundo seu segmento social ou pertencimento racial, refletindo sobre a singularidade e o papel das famílias no desempenho escolar dos filhos.

Após mapearmos os trabalhos e seus focos, observamos que, em algum período dos 13 anos analisados, cada foco temático apresentava um número maior de trabalhos, configurando uma tendência. No Gráfico 1, que segue, podemos visualizar esse movimento.

Gráfico 1 - Número de trabalhos de cada tendência por ano de apresentação nas reuniões anuais da ANPEd (2000-2013)

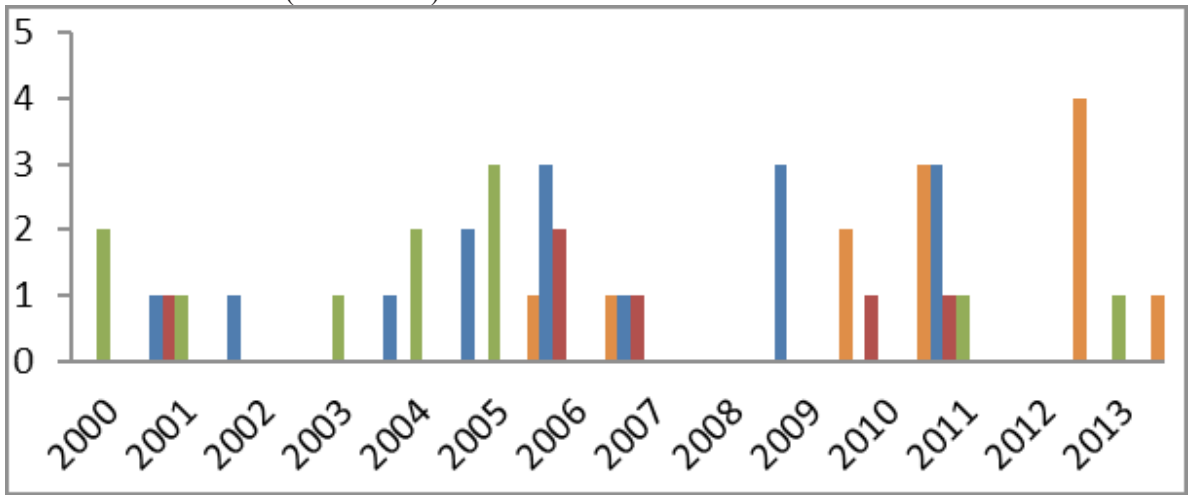

Interação

Representação

Políticas Educacionais

Práticas e Perfis Familiares

Fonte: o autor.

Observam-se as quatro cores representando cada tendência e o seu movimento na produção do conhecimento sobre a relação escola e família. Na primeira metade, que corresponde aos anos 2000 a 2006, registra-se a maior produção das tendências interação e representações. No final desse período, já encontramos dois trabalhos que representam as tendências politicas educacionais e práticas e perfis familiares. Porém, é na segunda metade, entre 2007 e 2013, que essas tendências se apresentam com o número maior de trabalhos, principalmente práticas e perfis familiares.

Cabe ressaltar que as tendências devem ser entendidas como algo complexo e dinâmico. Não há um corte, uma ruptura entre uma tendência, e outra que marca seu início e fim. Ao contrário, há uma linha que costura essas tendências marcando seu movimento. Entretanto, como cada tendência se caracteriza? Para responder a 
essa pergunta, analisamos cada tendência, seus objetos de pesquisa e alguns resultados alcançados.

\subsection{INTERAÇÃO}

A relação entre escola e famílias configura-se a partir das interações entre profissionais das instituições educativas e mães, pais, irmãos, avós e outros. Essas interações podem acontecer de diferentes formas, mas há um consenso entre as pesquisas que, para o sucesso escolar, o envolvimento das famílias é importante. Podemos observar essa inferência a partir dos trabalhos dessa tendência que são mais produzidos entre os anos de 2000 e 2005, conforme demonstrado no Gráfico 2.

Gráfico 2 - Número de trabalhos da tendência interação nas reuniões anuais da ANPEd (2000-2013)

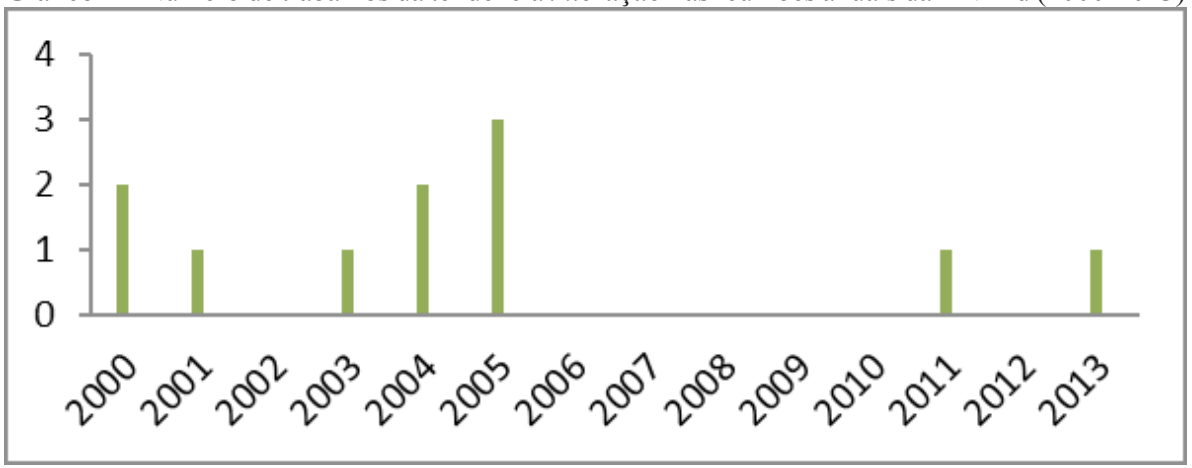

Fonte: o autor.

Podemos visualizar a primeira tendência aparecendo nos trabalhos comunicados nas reuniões anuais da ANPEd a partir do ano 2000. E essa tendência é investigada pela Sociologia e pela Psicologia da Educação, pois dos 11 trabalhos, sete são do GT da Sociologia da Educação e quatro da Psicologia da Educação. Esses trabalhos contribuem para a análise de três objetos de pesquisa: os momentos de interação, a interação como maior possibilidade de sucesso escolar e os sujeitos de interação.

Os momentos de interação são destacados por Bhering e Machado (2004) e Carvalho (2003). O primeiro trabalho descreveu os contatos diários entre professoras da Educação Infantil com as famílias. A análise dos dados demonstrou que as interações são estabelecidas para falar sobre os cuidados para com as crianças. O segundo trabalho analisa a interação da família por meio do dever de casa e revela que este tem dependido da doação do tempo das mães, sobrecarregando aquelas que trabalham 
fora de casa. Essas condições apontam para um modelo familiar que conta com a mãe com tempo livre.

O eixo que investiga a interação das famílias com a escola como maior possibilidade de sucesso escolar destaca que, quanto maior o envolvimento das famílias com a escolarização dos filhos, maiores as chances de sucesso escolar (MANDERLET, 2005; FRELLER, 2000) e que a aliança entre famílias e escola é marca das boas escolas (SILVA, 2011). Outra constatação foi que a mobilização da família no cotidiano escolar e a qualidade do ensino fornecido pela escola podem ter impacto positivo no desempenho dos alunos (BRANDÃO et al. 2004; MAIMONE; SCRIPTORI, 2005; SANTO, 2013).

Esse eixo começa a ser contestado quando se analisam os trabalhos sobre os sujeitos de interação. Nele, há três pesquisas que destacam a interação das famílias em diferentes contextos, como os designados de exclusão social (THISTED, 2000), do meio rural (SILVA, 2001) e na contemporaneidade (NOGUEIRA, 2005). Observamos um movimento de reflexão sobre a necessidade de se distinguirem melhor as variáveis e os contextos para a afirmação de que a interação com as famílias é o meio para se alcançar o sucesso escolar. Nogueira $(2005$, p. 4) ainda ressalta que "[...] novas dinâmicas sociais vêm afetando, ao mesmo tempo, a instituição familiar e o sistema escolar, levando ao aparecimento de novos traços e desenhando novos contornos nas relações entre essas duas grandes instâncias de socialização."

O discurso de que a interação da família com a escola é a responsável pelo sucesso escolar começa a ser questionada. Observamos, dessa forma, na tendência que segue, o movimento de investigação sobre as representações da relação escola e família a partir dos sujeitos dessa relação: pais, professores e alunos. Pesquisar quem são, o que sabem e o que pensam pode auxiliar na definição dos novos traços e contornos dessa relação.

\subsection{REPRESENTAÇÕES}

A tendência representações tem o maior número de publicações entre os anos 2004 e 2007, conforme se observa no Gráfico 3 a seguir, e se configura pela caracterização das concepções, perspectivas, expectativas e significados dos envolvidos na relação escola e família. 
Gráfico 3 - Número de trabalhos da tendência representações nas reuniões anuais da ANPEd (2000-2013)

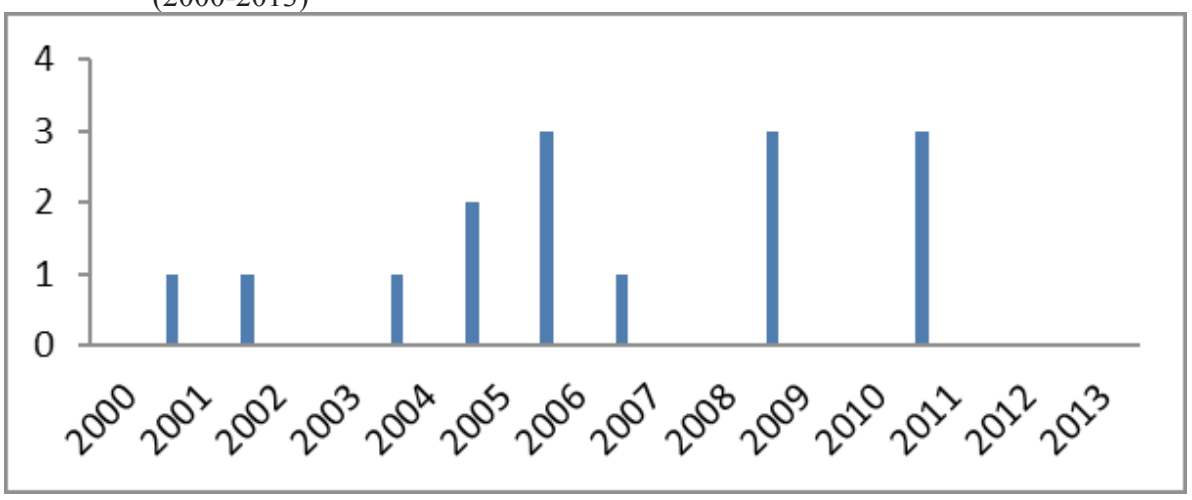

Fonte: o autor.

Percebemos a necessidade de se ouvirem os envolvidos nessa relação e se identificarem suas representações sobre alguns temas que envolvem a escola e a família. São 15 trabalhos representados pelos Grupos de Trabalho: Educação de Crianças de 0 a 6 anos, com seis trabalhos, Sociologia da Educação, com quatro, Ensino Fundamental, com três trabalhos, e Educação Especial, com dois.

Alguns autores investigaram a perspectiva de professores sobre a interação escola-família. Essas pesquisas apontam resultados que demonstram que o discurso dos professores se encontra preso a modelos desgastados na interação com as famílias (CABRAL; BERTOLUCI; TUBERO, 2006). Outro fato é que a representação dos professores sobre as funções dos pais na escola privilegia acompanhar o desenvolvimento escolar e frequentar reuniões, funções decorrentes de determinações da escola (MAURÍCIO, 2006). Conclui-se que, se os professores mudarem o modo pelo qual as famílias e sua participação na escola são concebidas, pode ser possível estabelecer interações mais positivas entre essas agências socializadoras (TRANCREDI; REALI, 2001).

Outras pesquisas investigaram com famílias, professores e alunos os sentidos e os significados de infância (ARAÚJO, 2009), a visão de mães e de professoras sobre o dever de casa (CARVALHO; BURITY, 2005), a socialização na escola (PAIXÃO; CRUZ; MELO, 2008) e a concepção de pais e alunos sobre a progressão continuada (GLORIA, 2002; JACOMINI, 2008).

Alguns autores ouviram as famílias investigando suas concepções, suas expectativas e suas perspectivas sobre diversos aspectos, como: o sistema público 
de Educação Infantil, a inserção das crianças na creche, a expectativa das famílias do meio rural sobre a educação pública para os filhos pequenos, o que as crianças fazem na creche, a importância do dever de casa para as famílias e o contexto de escolarização do aluno com deficiência (RESENDE, 2006; BHERING; SARKIS, 2007; DORZIAT, 2007; MORO, 2004; CASANOVA, 2011; MARTINS, 2011; SOBRINHO, 2010).

É importante destacar que investigar o que as famílias sabem e entendem sobre algumas questões do processo educativo se torna importante para entender o processo sob outra perspectiva. Referenciamos uma metáfora utilizada por Saraceno e Naldini (2003) que nos faz pensar a família como um tecido de vários fios que formam um desenho, "[...] mas quando se distingue um fio antes oculto, ou não visto, a percepção do desenho modifica-se.” (SARACENO; NALDINI, 2003, p. 23). É nesse sentido que a tendência representações aparece, para investigar a partir de todos os envolvidos na relação escola e família, possibilitando um novo desenho tanto para a escola quanto para as famílias. Esse novo desenho começa a ser pensado, também, a partir das políticas públicas educacionais.

\subsection{POLÍTICAS EDUCACIONAIS}

A tendência políticas educacionais é a que representa a menor produção dentro dos estudos sobre a relação família e escola. Seu movimento se fortalece após o ano 2006 e destaca-se em dois períodos, nos anos 2006/2007 e 2010/2011, como se observa no Gráfico 4, a seguir.

Gráfico 4 - Número de trabalhos da tendência politicas educacionais nas reuniões anuais da ANPEd (2000-2013)

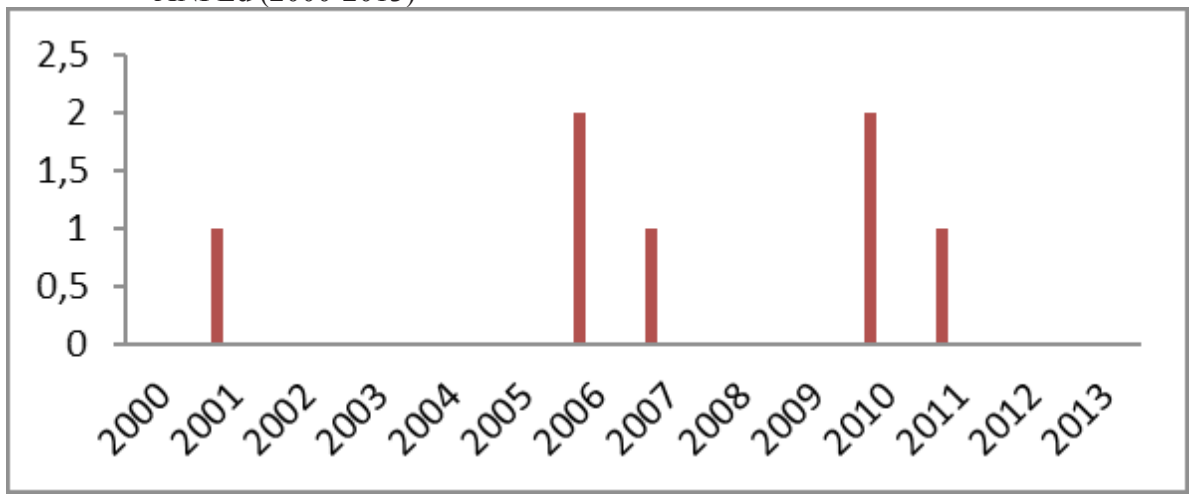

Fonte: o autor. 
Esses dois períodos bem marcados no Gráfico 4 podem nos remeter, como hipótese, às políticas estabelecidas nos anos que os antecedem, como, por exemplo, em 2004, o Programa Nacional de Fortalecimento dos Conselhos Escolares e, em 2008, o Plano de Mobilização Social pela Educação.

Como representação da área, percebemos que, dos seis trabalhos, três são do GT do Estado e Política Educacional, dois, do GT da Educação de Crianças de 0 a 6 anos e um da Psicologia da Educação. A maioria dos trabalhos tem seu foco na gestão democrática (ANDRADE, 2001; CORREA, 2006; SILVA, 2007; MARQUES; NASCIMENTO, 2011), enquanto dois outros desenvolvem a pesquisa a partir da progressão continuada (MARCONDES; SIGOLO, 2006) e a política pública para a criança pequena (FILHO, 2010).

Os resultados das pesquisas apontam que há o desafio de expandir o espaço de participação das famílias nas escolas e que isso interferiria na construção de uma cultura democrática das relações. Registramos uma multiplicidade de práticas de participação com formatos e intenções diversas, mas que acabam sendo desconsideradas como válidas por se afastarem do modelo preconizado. Outros resultados revelam que a maioria das famílias se mobiliza para participar e que as escolas podem aperfeiçoar o funcionamento de mecanismos já existentes. Uma das pesquisas também enfatiza que a investigação sobre a gestão democrática é um tema pouco explorado na Educação Infantil.

Cabe ressaltar que há mais 10 trabalhos que desenvolvem sua pesquisa a partir da gestão democrática, porém, seu objeto de estudo não é a relação com as famílias, mas a escolha dos dirigentes escolares, a prática escolar, suas bases epistemológicas, políticas e pedagógicas. Observamos grande interesse pela investigação da gestão democrática como política educacional, mas seu foco nem sempre retrata a relação entre escola e família. Diante disso, há muito que se pesquisar, como, por exemplo: de que formas as famílias participam dos processos escolares? A gestão democrática garante a efetiva participação de um número expressivo de famílias? Que tipo de participação se configura? Há diferenças na participação das famílias entre os níveis de ensino?

Essas perguntas e os dados apresentados no Gráfico 4 refletem a escassez de pesquisas sobre as políticas educacionais que induzem sobre as relações escola e famílias. Em contrapartida, a próxima tendência, denominada práticas e perfis familiares, retrata uma maior produção e permite identificar uma sistematização nas investigações. 


\subsection{PRÁTICAS E PERFIS FAMILIARES}

A tendência práticas e perfis familiares caracteriza-se por pesquisas que buscam por singularidades, por características das famílias na relação delas com a escola. Essa tendência representa $27,2 \%$ da produção dos trabalhos. No Gráfico 5, observamos essa tendência aparecendo nos anos 2005 e 2006 e fortalecendo-se a partir do ano 2009.

Gráfico 5 - Número de trabalhos da tendência práticas e perfis familiares nas reuniões anuais da ANPEd (2000-2013)

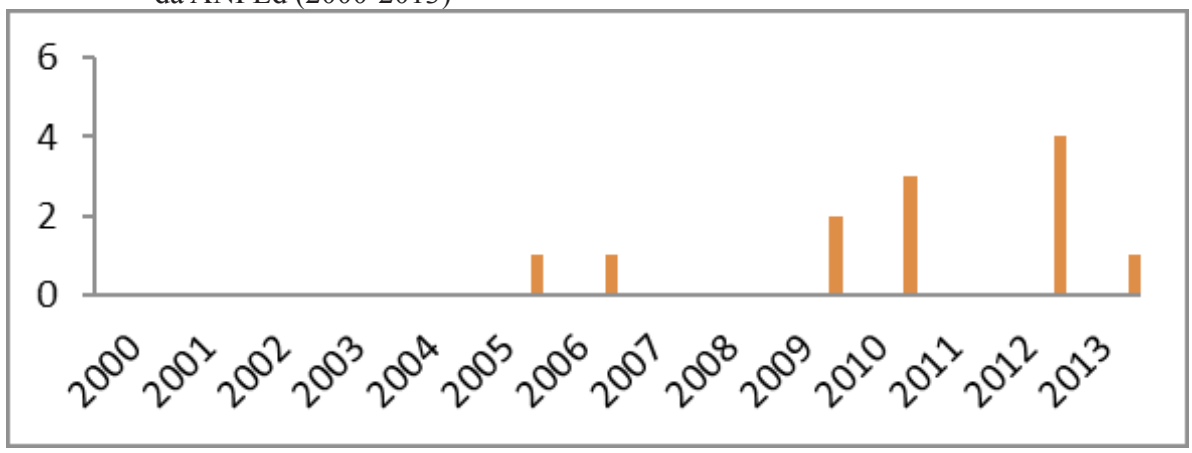

Fonte: o autor.

Dos 12 trabalhos que representam essa tendência, um é do GT do Trabalho e Educação, um é do GT dos Afro-brasileiros e 10 deles são do GT da Sociologia da Educação. Esse é um número representativo, pois define a Sociologia da Educação e suas bases teóricas como a área que desenvolve a discussão sobre a relação escola e família, sistematiza os estudos e propõe a continuidade e o interesse pelo tema. Em nenhuma outra tendência observamos um GT representado de forma tão específica.

As pesquisas desenvolvidas retratam o contexto microssocial das relações entre escola e família sem abandonar os determinantes macros. Os trabalhos desenvolvem uma discussão acerca do papel das famílias na produção do sucesso escolar e buscam as concepções e as práticas educacionais familiares em diferentes contextos: famílias de meios populares, de alta vulnerabilidade social (RESENDE et al., 2009; SILVA, 2012; ROCHA; BONAMINO, 2012), famílias negras de meios populares (SILVA, 2008), escolas públicas e particulares (BRANDÃO, 2010; NOGUEIRA et al., 2012), associação entre repetência escolar, características familiares e motivação do aluno (CORREA, 2012), escolha por estabelecimentos escolares (ALVES; OLIVEIRA; FISCH, 2010; RESENDE; NOGUEIRA; VIANA, 2013), influência da fa- 
mília na formação dos trabalhadores (SANTOS, 2005, 2006) e análise do tamanho da família e sua interferência na escolarização dos filhos (GLÓRIA, 2008).

Por meio dessas pesquisas, podemos definir o conjunto de fatos que se estabelecem nas configurações das famílias, pois, como define Lahire (1995, p. 72), “[...] o fato de os diferentes membros das famílias contextualizadas agirem como agem, de seus filhos serem o que são e comportarem-se como tal nos espaços escolares não é fruto de causas únicas que agiriam poderosamente sobre eles.” As famílias estão envolvidas em um conjunto de fatos que as tornam o que são.

Por meio de autores como Lahire, Montandon, Perrenoud, Singly, os quais se inspiraram nos estudos de Bourdieu, foi possível ampliar as bases teóricas da Sociologia da Educação. As pesquisas sobre escolarização e a atuação das famílias na escola ganharam novo olhar para apreender os vínculos entre as duas instituições (ROMANELLI; NOGUEIRA; ZAGO, 2013).

Os dados revelam uma vasta produção do campo da Sociologia da Educação que contribui para a compreensão da família como um "[...] complexo agente social mergulhado em múltiplos processos interativos com a sociedade em que se insere: nem puramente passiva, nem absolutamente autônoma." (SARACENO; NALDINI, 2003, p. 23). Observamos, assim, o grande movimento da área da Sociologia da Educação na investigação da relação escola e família nas reuniões anuais da ANPEd e sua contribuição na compreensão das escolas como fenômenos sociais.

\section{CONSIDERAÇÕES FINAIS}

A busca por trabalhos sobre a relação escola e família, entre os anos 2000 e 2013, no portal da Associação Nacional de Pós-graduação e Pesquisadores em Educação (ANPEd) revela alguns apontamentos que nos permitem visualizar o campo da relação escola e família de uma forma mais alargada nas reuniões anuais.

Por intermédio da busca pelos trabalhos em todos os Grupos, selecionamos 44, e a análise desse material aconteceu em dois momentos. No primeiro, agrupamos os trabalhos por GT, o que nos possibilitou observar a representação das diferentes áreas. Atentamos para o GT da Sociologia da Educação, que representa quase metade das pesquisas apresentadas, com 21 trabalhos, seguido do GT da Educação de Crianças de 0 a 6 anos, com oito trabalhos. Já a minoria das pesquisas, 22\%, está relacionada à Educação Infantil.

O segundo momento da análise desenvolveu-se a partir da leitura e do reconhecimento da questão central de cada trabalho. Essa leitura levou-nos a quatro 
categorias definidas a posteriori e que descrevemos como o movimento das pesquisas. Entre os anos 2000 e 2005, observamos o maior número de trabalhos com a questão central interação. Nessa tendência, discute-se a importância da relação família e escola no sucesso escolar e a necessidade de se distinguirem melhor as variáveis e os contextos para a afirmação de que a interação com as famílias é o meio para se alcançar o sucesso escolar.

Entre os anos 2004 e 2007, encontramos um número elevado de trabalhos da tendência representações. Aqui, as pesquisas caracterizam-se na busca das concepções, das perspectivas, das expectativas e dos significados dos envolvidos na relação escola e família. O objetivo era investigar além do ponto de vista da escola, mas com todos os envolvidos na relação escola e família, possibilitando um novo desenho para essa relação.

Na tendência políticas educacionais, com maior número de trabalhos entre os anos 2006 e 2011, encontramos a escassez de pesquisas sobre as políticas educacionais que induzem sobre as relações escola e famílias. A maioria tem como objeto de pesquisa a gestão democrática, mas ainda é um número restrito de trabalhos que não conseguem dar maior visibilidade ao tema.

A última tendência, práticas e perfis familiares, com maior produção entre os anos 2009 e 2013, é representada pelo GT da Sociologia da Educação e suas bases teóricas. As pesquisas contribuem para a compreensão das escolas como fenômenos sociais e retratam o contexto microssocial das relações entre escola e família sem abandonar os determinantes macros.

As conclusões com este trabalho permitiram-nos conhecer de forma mais ampla as discussões acerca da relação escola e família nas reuniões anuais da ANPEd entre os anos 2000 e 2013. A ANPEd, uma associação que reúne pesquisadores de diferentes áreas, fomenta a discussão e revela-nos dados que contribuem para o aprofundamento e a sistematização dos estudos, bem como para a comunicação de novas questões de pesquisa e bases teóricas.

Nota explicativa

${ }^{1} \mathrm{O}$ termo escola, utilizado neste artigo, é sinônimo de instituição educativa, entendida como creches, pré-escolas e escolas do Ensino Fundamental e Médio. 


\section{REFERÊNCIAS}

ALVES, F. C. de M.; OLIVEIRA, A. L. R. de; FISCH, G. Escolhas por estabelecimentos escolares: efeitos das características das famílias e do contexto de moradia. In: REUNIÃO ANUAL DA ANPED, 33., 2010, Caxambu, MG. Anais eletrônicos... Caxambu, 2010. Disponível em: <http://33reuniao.anped.org.br/33encontro/app/ webroot/files/file/Trabalhos\%20em\%20PDF/GT14-6402--Int.pdf>. Acesso em: 15 jan. 2015.

ANDRADE, M. Políticas de autonomia escolar y participación de las famílias em la escolarización: tendências del caso argentino. In: REUNIÃO ANUAL DA ANPED, 24., 2001, Caxambu, MG. Anais eletrônicos... Caxambu, 2001. Disponível em: $<$ http://24reuniao.anped.org.br/tp.htm>. Acesso em: 15 jan. 2015.

ARAÚJO, D. S. Infância: sentidos e significados atribuídos por familiares e educadores de creche. In: REUNIÃO ANUAL DA ANPED, 32., 2009, Caxambu, MG. Anais eletrônicos... Caxambu, 2009. Disponível em: $<$ http://32reuniao.anped.org. br/arquivos/trabalhos/GT07-5627--Int.pdf>. Acesso em: 25 fev. 2010.

BHERING, E.; GARCIA, S. E. K. O envolvimento de pais em creche de periferia: um estudo sobre as expectativas dos pais e o trabalho desenvolvido em creche por suas atendentes, monitoras e crianças. In: SEMINÁRIO ANUAL DE INICIAÇÃO CIENTÍFICA, 8., 1999, Cascavel. Anais... Cascavel: Universidade Estadual do Oeste do Paraná, 1999.

BHERING, E.; GARCIA, S. E. K. Um estudo sobre as expectativas dos pais para o trabalho desenvolvido por atendentes e crianças em uma creche de iniciativa voluntária. Alcance, Itajaí, v. 8, n. 5, p. 15-38, 2001.

BHERING, E.; MACHADO, G. Um estudo sobre os encontros diários entre professoras e pais em duas instituições de educação infantil. In: REUNIÃO ANUAL DA ANPED, 27., 2004, Caxambu, MG. Anais eletrônicos... Caxambu, 2004. Disponível em: <http://27reuniao.anped.org.br/gt15/t152.pdf>. Acesso em: 06 jun. 2009.

BHERING, E.; NEZ, T. B. Envolvimento de pais em creche: possibilidades e dificuldades de parceria. Psicologia. Teoria e Pesquisa, Brasília, v. 18, n. 1, p. 63-73, jan./abr. 2002.

BHERING, E.; SARKIS, A. A inserção de crianças na creche: um estudo sobre a perspectiva dos pais. In: REUNIÃO ANUAL DA ANPED, 30., 2007, Caxambu, MG. Anais eletrônicos... Caxambu, 2007. Disponível em: <http://30reuniao.anped. org.br/trabalhos/GT07-3293--Int.pdf>. Acesso em: 30 maio 2009. 
BRANDÃO, Z. Práticas cotidianas na escola e na família. Hipóteses sobre a constituição de habitus escolares. In: REUNIÃO ANUAL ANPED, 33., 2010, Caxambu, MG. Anais eletrônicos... Caxambu, 2010. Disponível em: <http://33reuniao.anped. org.br/33encontro/app/webroot/files/file/Trabalhos\%20em\%20PDF/GT14-6304--Int. pdf $>$. Acesso em: 15 jan. 2015.

BRANDÃO, Z. et al. Processo de produção de qualidade de ensino: escola, família e cultura. In: REUNIÃO ANUAL DA ANPED, 27., 2004, Caxambu, MG. Anais eletrônicos... Caxambu, 2004. Disponível em: <http://27reuniao.anped.org.br/gt14/ t147.pdf>. Acesso em: 06 jun. 2009.

BRASIL. Constituição. República Federativa do Brasil. Brasília, DF: Senado Federal, 1988. Disponível em: <http://www.planalto.gov.br/ccivil_03/constituicao/ ConstituicaoCompilado.htm>. Acesso em: 15 jan. 2015.

CABRAL, A. B.; BERTOLUCI, E.; TÚBERO, R. A. A interação escola-família sob a perspectiva de professores do ensino fundamental em uma escola estadual. In: REUNIÃO ANUAL DA ANPED, 29., 2006, Caxambu, MG. Anais eletrônicos... Caxambu, 2006. Disponível em: <http://webcache.googleusercontent.com/ search?q=cache:9ejnwgJdFeYJ:28reuniao.anped.org.br/textos/GT13/gt131488int. $\mathrm{rtf}+\& \mathrm{~cd}=1 \& \mathrm{hl}=\mathrm{pt}-\mathrm{BR} \& \mathrm{ct}=\mathrm{clnk} \& \mathrm{gl}=$ br $>$. Acesso em: 06 jun. 2009.

CARVALHO, M. E. P. de; BURITY, M. H. Dever de casa: visões de mães e professoras. In: REUNIÃO ANUAL DA ANPED, 28., 2005, Caxambu, MG. Anais eletrônicos... Caxambu, 2005. Disponível em: <http://webcache.googleusercontent. com/search?q=cache:oz42sK_cc_sJ:28reuniao.anped.org.br/textos/gt14/gt141575int. $\mathrm{rtf}+\& \mathrm{~cd}=2 \& \mathrm{hl}=\mathrm{pt}-\mathrm{BR} \& \mathrm{ct}=\mathrm{clnk} \& \mathrm{gl}=\mathrm{br}>$. Acesso em: 06 jun. 2009.

CARVALHO, M. E. P. de. O dever de casa e as relações família-escola. In: REUNIÃO ANUAL DA ANPED, 26., 2003, Caxambu, MG. Anais eletrônicos... Caxambu, 2003. Disponível em: <http://26reuniao.anped.org.br/>. Acesso em: 15 jan. 2015.

CASANOVA, L. O que as crianças fazem na creche? As famílias respondem. In: REUNIÃO ANUAL DA ANPED, 34., 2011, Natal, RN. Anais eletrônicos... Natal, 2011. Disponível em: <http://34reuniao.anped.org.br/images/trabalhos/GT07/GT07240\%20int.pdf>. Acesso em: 13 mar. 2012.

CORREA, B. C. A gestão democrática como referencial de qualidade na educação infantil para crianças de 4 a 6 anos. In: REUNIÃO ANUAL DA ANPED, 29., 2006, Caxambu, MG. Anais eletrônicos... Caxambu, 2006. Disponível em: $<$ http://29reuniao.anped.org.br/trabalhos/trabalho/GT07-2163--Int.pdf > . Acesso em: 06 jun. 2009. 
CORREA, E. V. Origem familiar, características e motivação do aluno: quais as relações com o aumento ou diminuição do risco de repetência no final do primeiro segmento do ensino fundamental? In: REUNIÃO ANUAL DA ANPED, 35., 2012, Porto de Galinhas, PE. Anais eletrônicos... Porto de Galinhas, 2012. Disponível em: $<$ http://35reuniao.anped.org.br/images/stories/trabalhos/GT14\%20Trabalhos/GT142383 int.pdf $>$. Acesso em: 15 jan. 2015.

CORSINO, P. Relação família e escola na Educação Infantil: algumas reflexões. Boletim Salto para o Futuro. TV Escola, Brasília: Secretaria da Educação à distância. Ministério da Educação, 2002. Disponível em: <www.redebrasil.tv.br/salto/boletins2002 >. Acesso em: 22 maio 2009.

DORZIAT, A. A família no contexto da inclusão. In: REUNIÃO ANUAL DA ANPED, 30., 2007, Caxambu, MG. Anais eletrônicos... Caxambu, 2007. Disponível em: < http://30reuniao.anped.org.br/trabalhos/GT15-3171--Int.pdf > . Acesso em: 06 jun. 2009.

FILHO, A. G. L. O foco nas mães adia a expansão da educação infantil no Brasil. In: REUNIÃO ANUAL DA ANPED, 33., 2010, Caxambu, MG. Anais eletrônicos... Caxambu, 2010. Disponível em: <http://33reuniao.anped.org.br/33encontro/app/ webroot/files/file/Trabalhos\%20em\%20PDF/GT07-6067--Int.pdf>. Acesso em: 04 nov. 2014.

FRELLER, C. C. Trabalhando com pais sobre indisciplina escolar: um desafio para o psicólogo. In: REUNIÃO ANUAL DA ANPED, 23., 2000, Caxambu, MG. Anais eletrônicos... Caxambu: Hotel Glória, 2000. Disponível em: $<$ http://23reuniao. anped.org.br/textos/2001t.PDF>. Acesso em: 15 jan. 2015.

GLÓRIA, D. M. A. A “escola dos que passam sem saber”: a prática da não-retenção escolar na narrativa de alunos e familiares. In: REUNIÃO ANUAL DA ANPED, 25., 2002, Caxambu, MG. Anais eletrônicos... Caxambu, 2002. Disponível em: $<$ http://25reuniao.anped.org.br/tp251.htm\#gt14>. Acesso em: 15 jan. 2015.

GLÓRIA, D. M. A. O tamanho da família como fator sociodemográfico a interferir na escolarização dos filhos. In: REUNIÃO ANUAL DA ANPED, 31., 2008, Caxambu, MG. Anais eletrônicos... Caxambu, 2008. Disponível em: $<$ http://31 reuniao. anped.org.br/1trabalho/GT14-4174--Int.pdf>. Acesso em: 04 nov. 2014.

JACOMINI, M. A. Concepções de pais e alunos sobre ciclos e progressão continuada na rede municipal de ensino de São Paulo. In: REUNIÃO ANUAL DA ANPED, 31., 2008, Caxambu, MG. Anais eletrônicos... Caxambu, 2008. Disponível em: $<$ http://31 reuniao.anped.org.br/1 trabalho/GT13-4213--Int.pdf >. Acesso em: 14 nov. 2014. 
KISHIMOTO, T.; HADDAD, L. Família moderna em contexto: o caso do Brasil. In: CONGRESSO LATINO-AMERICANO DE CRECHES, 2., 1995, Rio de Janeiro. Anais... Rio de Janeiro: Asbrac, 1995.

KUHLMANN JÚNIOR, M.; FERNANDES, R. Sentidos da infância. In: FARIA FILHO, L. M. de. (Org.). A Infância e sua Educação. Belo Horizonte: Autêntica, 2004.

LAHIRE, B. Sucesso escolar nos meios populares: as razões do improvável. São Paulo: Ática, 1995.

MAIMONE, E. H.; SCRIPTORI, C. C. Estratégias de participação de pais no processo de formação continuada de professores em creche. In: REUNIÃO ANUAL DA ANPED, 28., 2005, Caxambu, MG. Anais eletrônicos... Caxambu, 2005. Disponível em: <http://28reuniao.anped.org.br/gt20.htm>. Acesso em: 15 jan. 2015.

MANDERLET, D. Pais na gestão da escola: mudam as relações? A análise sociológica de uma instituição judaica. In: REUNIÃO ANUAL DA ANPED, 29., 2006, Caxambu, MG. Anais eletrônicos... Caxambu, 2006. Disponível em: <http://29reuniao. anped.org.br/trabalhos/trabalho/GT14-1706--Int.pdf>. Acesso em: 06 jun. 2009.

MARCONDES, K. H. B.; SIGOLO, S. R. R. L. A relação entre a família e a escola no contexto de progressão continuada. In: REUNIÃO ANUAL DA ANPED, 29., 2006, Caxambu, MG. Anais eletrônicos... Caxambu, 2006. Disponível em: $<$ http://29reuniao.anped.org.br/trabalhos/trabalho/GT20-2173--Int.pdf >. Acesso em: 06 jun. 2009.

MARQUES, L. R.; NASCIMENTO, P. X. S. de. As interfaces da participação da família na gestão escolar. In: REUNIÃO ANUAL DA ANPED, 34., 2011, Natal, RN. Anais eletrônicos... Natal, 2011. Disponível em: <http://34reuniao.anped.org. br/images/trabalhos/GT05/GT05-737\%20int.pdf >. Acesso em: 15 jan. 2015.

MARTINS, R. K. Expectativas das famílias do meio rural em relação à educação pública para os filhos menores de quatro anos. In: REUNIÃO ANUAL DA ANPED, 34., 2011, Natal, RN. Anais eletrônicos... Natal, 2011. Disponível em: $<$ http://34reuniao.anped.org.br/index.php?option $=$ com_content\&view $=$ article\&id $=$ 106:trabalhos-gt07-educacao-de-criancas-de-0-a-6-anos\&catid=47:trabalhos\&Item $\mathrm{id}=59>$. Acesso em: 06 jun. 2009.

MAURÍCIO, L. V. A participação dos pais na ótica dos professores. In: REUNIÃO ANUAL DA ANPED, 28., 2005, Caxambu, MG. Anais eletrônicos... Caxambu, 2005. Disponível em: <http://28reuniao.anped.org.br/textos/GT13/gt13414int.rtf>. Acesso em: 06 jun. 2009. 
MORO, C. de S. As concepções sobre o sistema público de educação infantil de mães que utilizam e que não utilizam creches. 2004. Disponível em: <http://www. anped.org.br/reunioes/27/gt07/t071.pdf>. Acesso em: 14 jun. 2009.

NOGUEIRA, M. A. Família e escola na contemporaneidade: os meandros de uma relação. In: REUNIÃO ANUAL DA ANPED, 28., 2005, Caxambu, MG. Anais eletrônicos... Caxambu, 2005. Disponível em: <http://28reuniao.anped.org.br/textos/ gt14/gt14214int.rtf>. Acesso em: 06 jun. 2009.

NOGUEIRA, M. A. et al. Família e desempenho escolar: uma análise exploratória da associação entre fatores familiares e proficiência em Língua Portuguesa. In: REUNIÃO ANUAL DA ANPED, 35., 2012, Porto de Galinhas, PE. Anais eletrônicos... Porto de Galinhas, 2012. Disponível em: <http://35reuniao.anped.org.br/images/stories/trabalhos/GT14\%20Trabalhos/GT14-1504_int.pdf>. Acesso em: 14 nov. 2014.

PAIXÃO, L. P.; CRUZ, L. da; MELO, M. B. Socialização na escola: consonâncias e dissonâncias entre mães, professoras e alunos. In: REUNIÃO ANUAL DA ANPED, 31., 2008, Caxambu, MG. Anais eletrônicos... Caxambu, 2008. Disponível em: $<$ http://31 reuniao.anped.org.br/1 trabalho/GT14-4261--Int.pdf > . Acesso em: 14 nov. 2014.

RESENDE, T. de F. Dever de casa: questões em torno de um consenso. In: REUNIÃO ANUAL DA ANPED, 29., 2006, Caxambu, MG. Anais eletrônicos... Caxambu, 2006. Disponível em: <http://29reuniao.anped.org.br/trabalhos/trabalho/ GT14-2625--Res.pdf>. Acesso em: 06 jun. 2009.

RESENDE, T. de F. et al. Perfis familiares e tipos de estabelecimentos de ensino: desafios e questões para a análise sociológica. In: REUNIÃO ANUAL DA ANPED, 32., 2009, Caxambu, MG. Anais eletrônicos... Caxambu, 2009. Disponível em: $<$ http://32reuniao.anped.org.br/arquivos/trabalhos/GT14-5508--Int.pdf > . Acesso em: 14 nov. 2014.

RESENDE, T. de F.; NOGUEIRA, C. M.; VIANA, M. J. B. Origem social, escolha do estabelecimento de ensino e desempenho escolar: um estudo com famílias de alunos das redes estadual e municipal de Belo Horizonte. In: REUNIÃO ANUAL DA ANPED, 36., 2013, Goiânia, GO. Anais eletrônicos... Goiânia, 2013. Disponível em: <http://36reuniao.anped.org.br/pdfs_trabalhos_aprovados/gt14_trabalhos_pdfs/ gt14_2967_texto.pdf>. Acesso em: 14 nov. 2014.

ROCHA, G. A. S.; BONAMINO, A. A preservação de cadernos escolares nos meios populares e o investimento familiar na escolarização dos filhos: possíveis relações. In: REUNIÃO ANUAL DA ANPED, 35., 2012, Porto de Galinhas, PE. Anais eletrônicos... Porto de Galinhas, 2012. Disponível em: <http://35reuniao.anped.org.br/ images/stories/trabalhos/GT14\%20Trabalhos/GT14-1973_int.pdf $>$. Acesso em: 14 nov. 2014. 
ROMANELli, G.; NOGUEIRA, M. A.; ZAGO, N. (Org.). Família \& Escola: novas perspectivas de análise. Petrópolis: Vozes, 2013.

ROSEMBERG, F. A criação de filhos pequenos: tendências e ambiguidades contemporâneas. In: RIBEIRO, I.; RIBEIRO, A. C. (Org.). Família em processos contemporâneos: inovações culturais na sociedade brasileira. São Paulo: Loyola, 1995.

ROSSETTI-FERREIRA, M. C.; AMORIM, K. de S. Observação da interação do bebê com a mãe e a educadora durante sua adaptação à creche. In: SIMPÓSIO BRASILEIRO DE OBSERVAÇÃO DA RELAÇÃO MÃE-BEBÊ, 1., 1997, São Paulo. Anais... São Paulo: Unimarco, 1997.

ROSSETTI-FERREIRA, M. C.; AMORIM, K. de S. Relações afetivas na família e na creche durante o processo de inserção de bebês. In: SIMPÓSIO LATINO AMERICANO DE ATENÇÃO A CRIANÇA DE 0-6 ANOS, 4., 1998, Brasília. Anais... Brasília, DF, 1998.

SANTO, A. M. de O. Relação família-escola e desempenho escolar: estudo em duas escolas da rede municipal do Rio de Janeiro. In: REUNIÃO ANUAL DA ANPED, 36., 2013, Goiânia, GO. Anais eletrônicos... Goiânia, 2013. Disponível em: <http://36reuniao.anped.org.br/pdfs_trabalhos_aprovados/gt14_trabalhos_pdfs/ gt14_3323_texto.pdf>. Acesso em: 14 nov. 2014.

SANTOS, A. V. dos. Influências da família e da escola na formação de trabalhadores: papéis coincidentes? In: REUNIÃO ANUAL DA ANPED, 29., 2006, Caxambu, MG. Anais eletrônicos... Caxambu, 2006. Disponível em: <http://29reuniao.anped. org.br/trabalhos/trabalho/GT14-2167--Int.pdf>. Acesso em: 06 jun. 2009.

SANTOS, A. V. dos. Os papéis da família e da escola na constituição dos sujeitos: implicações na formação dos trabalhadores. In: REUNIÃO ANUAL DA ANPED, 28., 2005, Caxambu, MG. Anais eletrônicos... Caxambu, 2005. Disponível em: $<$ http://28reuniao.anped.org.br/textos/gt09/gt09563int.doc $>$. Acesso em: 06 jun. 2009.

SARACENO, C.; NALDINI, M. Sociologia da Família. Lisboa: Editorial Estampa, 2003.

SILVA, F. C. da. O papel exercido por famílias negras e de meios populares na trajetória de escolarização dos filhos (Pernambuco, 1950-1970). In: REUNIÃO ANUAL DA ANPED, 31., 2008, Caxambu, MG. Anais eletrônicos... Caxambu, 2008. Disponível em: <http://31reuniao.anped.org.br/1trabalho/GT21-4186--Int.pdf>. Acesso em: 06 jun. 2009. 
SILVA, H. H. de C. A escola e famílias moradoras de territórios de alta vulnerabilidade social na metrópole: práticas educativas de famílias "protagonistas". In: REUNIÃO ANUAL DA ANPED, 35., 2012, Porto de Galinhas, PE. Anais eletrônicos... Porto de Galinhas, 2012. Disponível em: $<$ http://35reuniao.anped.org.br/images/stories/trabalhos/GT14\%20Trabalhos/GT14-2360_int.pdf >. Acesso em: 15 jan. 2015.

SILVA, I. M. da. A avaliação institucional e a gestão democrática na escola. In: REUNIÃO ANUAL DA ANPED, 30., 2007, Caxambu, MG. Anais eletrônicos... Caxambu, 2007. Disponível em: <http://30reuniao.anped.org.br/trabalhos/GT052830--Int.pdf $>$. Acesso em: 30 maio 2009.

SILVA, L. H. A relação escola-família no universo das experiências brasileiras de formação em alternância. In: REUNIÃO ANUAL DA ANPED, 24., 2001, Caxambu, MG. Anais eletrônicos... Caxambu, 2001. Disponível em: <http://24reuniao.anped. org.br/tp1.htm>. Acesso em: 15 jan. 2015.

SILVA, M. L. C. Q. da. Famílias e escola: uma relação em transformação frente aos desafios da sociedade contemporânea. In: REUNIÃO ANUAL DA ANPED, 34 ., 2011, Natal, RN. Anais eletrônicos... Natal, 2011. Disponível em: <http://34reuniao. anped.org.br/images/trabalhos/GT14/GT14-268\%20int.pdf>. Acesso em: 15 jan. 2015.

SOBRINHO, R. C. A relação de pais de alunos com deficiência e escola comum: dilemas e perspectivas. In: REUNIÃO ANUAL DA ANPED, 33., 2010, Natal, RN. Anais eletrônicos... Natal, 2010. Disponível em: $<$ http://33reuniao.anped.org. br/33encontro/app/webroot/files/file/Trabalhos\%20em\%20PDF/GT15-6770--Int. pdf $>$. Acesso em: 15 jan. 2015.

SOUSA, S. Z.; BIANCHETTI, L. Pós-graduação e pesquisa em educação no Brasil: o protagonismo da ANPED. Revista Brasileira de Educação, n. 36, p. 389-546, set./dez. 2007.

SZYMANSKI, H. A relação família/escola: desafios e perspectivas. Brasília, DF: Liber Livro, 2010.

THISTED, S. Familias y escuela em la trama de la desigualdade. In: REUNIÃO ANUAL DA ANPED, 23., 2000, Caxambu, MG. Anais eletrônicos... Caxambu: Hotel Glória, 2000. Disponível em: <http://23reuniao.anped.org.br/trabtit2.htm\#gt14>. Acesso em: 15 jan. 2015.

TOCI-DIAS, A. T. Pesquisando a relação família-escola: o que revelam as teses e dissertações dos programas de pós-graduações brasileiros. 2009. 219 p. Tese (Doutorado em Educação)-Universidade Estadual Paulista, 2009. 
TRANCREDI, M. R. S. P.; REALI, A. M. de M. R. Visões de professores sobre as famílias de seus alunos: um estudo na área da educação infantil. In: REUNIÃO ANUAL DA ANPED, 24., 2001, Caxambu, MG. Anais eletrônicos... Caxambu: Hotel Glória, 2001. Disponível em: <http://24reuniao.anped.org.br/tp.htm\#gt7>. Acesso em: 15 jan. 2015.

VASCONCELLOS, V. M. R. Como família e creche influenciam a educação infantil, na perspectiva da família. In: REUNIÃO ANUAL DE PSICOLOGIA, 31., 2001, Rio de Janeiro. Anais... Rio de Janeiro: Sociedade Brasileira de Psicologia, 2001.

VASCONCELLOS, V. M. R. O que pensam pais e professores sobre as práticas da Educação Infantil. In: SEMANA DE GRADUAÇÃO DA UERJ, 4., 2004, Rio de Janeiro. Anais... Rio de Janeiro: UERJ Sem Muros; CEPUERJ, 2004.

Recebido em 18 de agosto de 2015

Aceito em 17 de dezembro de 2015

Endereço para contato: Rua Uruguai, 458, Centro, 88302-901, Itajaí, Santa, Catarina, Brasil; leticiacasannova@gmail.com 
